\title{
钯催化烯烃的不对称马氏氢胺羰基化反应
}

\author{
田端帅汤文军* \\ (中国科学院上海有机化学研究所 上海 200032)
}

\section{Palladium-Catalyzed Asymmetric Markovnikov Hydroaminocarbonylation of Alkenes}

\author{
Tian, Duanshuai Tang, Wenjun* \\ (Shanghai Institute of Organic Chemistry, Chinese Academy of Sciences, Shanghai 200032)
}

一氧化碳参与的羰基化反应是有机合成中最重要 的反应之一. 烯烃的氢羰基化反应已经被广泛应用于药 物、材料及精细化学品的工业生产中 ${ }^{[1]}$. 例如, 乙烯的甲 氧羰基化反应被用于甲基丙烯酸甲酯的工业合成, 然 而, 该领域仍有许多挑战性难题尚未得到有效解决. 烯 烃的氢胺羰基化反应能以原子经济性的方式合成酰胺, 且已经实现该类反应的区域选择性控制，但是，如何同 时控制该类反应的区域选择性和对映选择性, 以简单易 得的烯烃和一氧化碳为底物直接合成手性酰胺类化合 物, 仍是一个悬而未决的重要难题.

西北大学化学与材料科学学院关正辉团队 ${ }^{[2-4]}$ 长期 从事一氧化碳的羰基化反应研究, 曾发展了钯催化氮烷 基芳胺的碳氢活化双羰基化、烯酰胺和吲哚的碳氢羰基 化等重要反应. 近期, 该研究团队在不对称羰基化反应 领域取得了重要进展. 他们利用一种新型亚磷酰胺配 体, 发展了钯催化不对称串联 Heck 羰基化反应, 该反 应对芳胺、芳基硼酸及醇等亲核试剂都能有效地兼容. 以该反应为关键步骤可以大大节约吡咯并吲哚类天然 产物的全合成步骤, 例如他们以 6 步 10.1\%的总收率实 现了天然生物碱 $(+)$-Folicanthine 的不对称全合成 (Scheme 1) ${ }^{[5]}$.

最近, 关正辉团队 ${ }^{[6]}$ 在烯烃氢胺羰基化反应方面取 得了新的进展, 他们利用钯催化剂和一种新型亚磷酰胺 配体, 成功实现了烯烃氢胺宸基化反应的区域选择性和 对映选择性控制(Scheme 2). 该反应在室温条件下进行, 对于各种烯烃和芳胺都具有较好的兼容性. 当以芳基烯 烃为底物时可以得到优异的产率、区域选择性和对映选 择性. 该反应具有优秀的官能团兼容性, 可以兼容硝

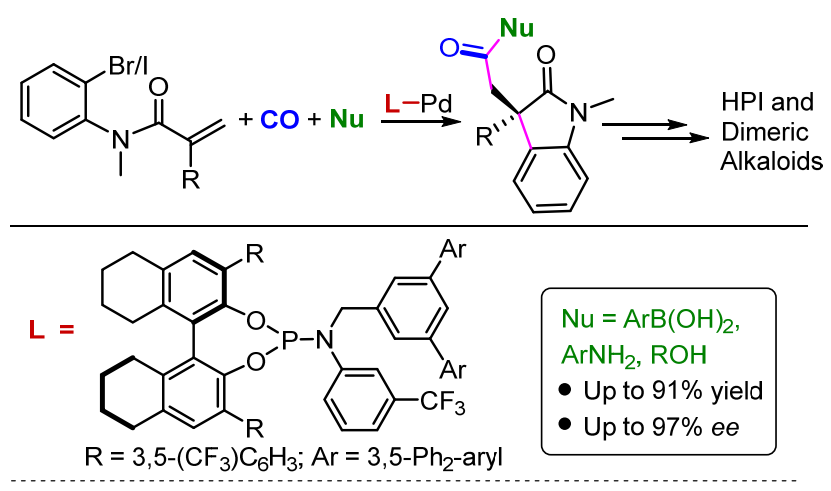

Asymmetric total synthesis of $(+)$-folicanthine:

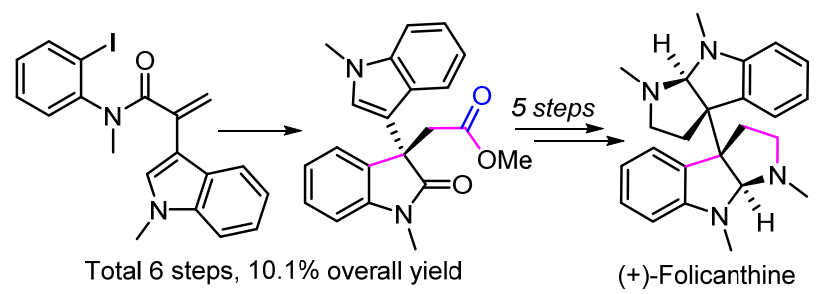

图式 1 钯催化不对称串联 Heck 羰基化反应

Scheme 1 Pd-catalyzed asymmetric domino Heck carbonylation reaction

基、溴和酚羟基等敏感官能团; 特别是当以氨基酚为底 物时，可以专一性地得到含酚着基的手性酰胺产物，为 兼具解热和抗炎作用的新颖结构药物提供了最简洁方 便的策略. 同时，作者通过水解获得的酰胺产物，高产 率、高对映选择性地合成了一系列手性非甾体抗炎药, 包括布洛芬、䒺普生、酮洛芬和氟比洛芬等.

作者对钯催化烯烃氢胺羰基化反应的机理进行了 研究, 氛代实验等研究表明反应经历了钯氢先对烯烃的 不可逆插入再羰基化偶联的机理(Scheme 3).

* Corresponding author. E-mail: tangwenjun@sioc.ac.cn. Published online January 22, 2021. 


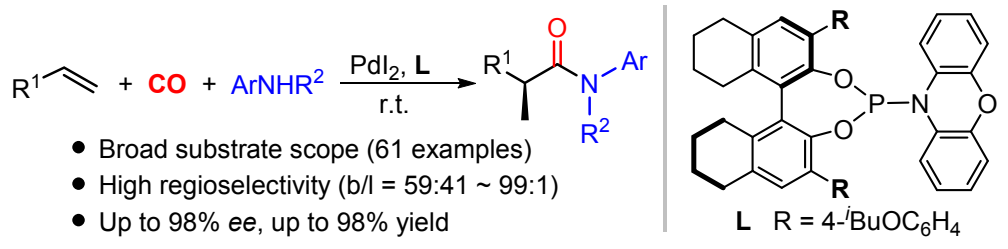<smiles>CCCc1cccc(CCC)c1NC(=O)C(C)c1ccccc1</smiles>

$62 \%$ yield, $93 \%$ ee<smiles>CC(C(=O)Nc1ccc(O)cc1)c1ccccc1</smiles>

$72 \%$ yield, $88 \%$ ee<smiles>CC(C(=O)Nc1cccc2cccnc12)c1ccccc1</smiles>

$96 \%$ yield, $89 \%$ ee<smiles>CC(C(=O)N1CCc2ccccc21)c1ccccc1</smiles>

$95 \%$ yield, $92 \%$ ee<smiles>CC(C(=O)Nc1ccccc1)c1ccc([N+](=O)[O-])cc1</smiles>

$62 \%$ yield, $90 \%$ ee<smiles>CC(C(=O)Nc1ccccc1)c1ccc(Br)cc1</smiles>

$82 \%$ yield, $94 \%$ ee<smiles>CC(=O)CC(C)C(=O)Nc1ccccc1</smiles>

$83 \%$ yield, $20 \%$ ee

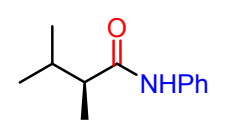

$74 \%$ yield, $57 \%$ ee<smiles>CCCNC(=O)C(C)C1CCCCC1</smiles>
$90 \%$ yield, $63 \%$ ee

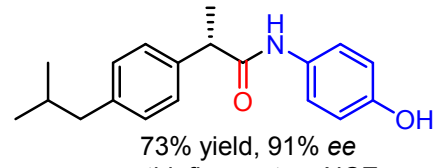<smiles>C[C@H](C(=O)Nc1ccccc1)c1cccc(C(=O)c2ccccc2)c1</smiles>

$76 \%$ yield, $93 \%$ ee<smiles>CC(C)Cc1ccc(C(C)C(=O)NPc2ccccc2)cc1</smiles>

$98 \%$ yield, $90 \%$ ee<smiles>CC(C)Cc1ccc([C@@H](C)C(=O)O)cc1</smiles>

ibuprofen<smiles>COc1ccc2cc(C(C)C(=O)Nc3ccccc3)ccc2c1</smiles>

图式 2 钯催化的烯烃的不对称氢胺羰基化反应

Scheme 2 Pd-catalyzed asymmetric hydroaminocarbonylation of alkenes with anilines

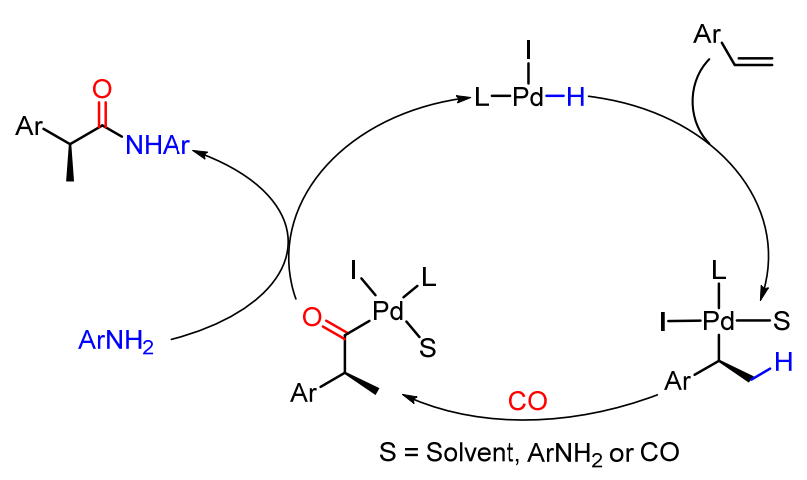

图式 3 钯催化氢胺羰基化反应的机理

Scheme 3 Tentative reaction mechanism of Pd-catalyzed hydroaminocarbonylation reaction

总之, 关正辉研究团队在他们前期关于钯催化羰基 化反应研究的基础上, 实现了钯催化烯烃的不对称马氏
氢胺羰基化反应. 该反应的条件温和，官能团兼容性好, 底物范围宽, 产率高, 区域和对映选择性好. 为手性 2取代丙酰胺类化合物及非甾体抗炎药菜普生、布洛芬和 酮洛芬等的高效合成提供了新的方法和策略.

\section{References}

[1] Tian, D.; Xu, R.; Zhu, J.; Huang, J.; Dong, W.; Claverie, J.; Tang, W. Angew. Chem., Int. Ed. DOI: 10.1002/anie. 202015450.

[2] Guan, Z.-H.; Chen, M.; Ren, Z.-H. J. Am. Chem. Soc. 2012, 134, 17490.

[3] Chen, M.; Ren, Z.-H.; Wang, Y.-Y.; Guan, Z.-H. Angew. Chem., Int Ed. 2013, 52, 14196 .

[4] Zhao, M.-N.; Ran, L.; Chen, M.; Ren, Z.-H.; Wang, Y.-Y.; Guan, Z.-H. ACS Catal. 2015, 5, 1210.

[5] Chen, M.; Wang, X.; Yang, P.; Kou, X.; Ren, Z.-H.; Guan, Z.-H. Angew. Chem., Int. Ed. 2020, 59, 12199.

[6] Yao, Y.-H.; Yang, H.-Y.; Chen, M.; Wu, F.; Xu, X.-X.; Guan, Z.-H. J. Am. Chem. Soc. 2021, 143, 85. 